\title{
A dashboard for security forces data visualization and storytelling
}

Miguel de Castro Neto, Nova Information Management School (NOVA IMS), Universidade Nova de Lisboa, Portugal, mneto@novaims.unl.pt

Marcel Nascimento, Nova Information Management School (NOVA IMS), Universidade Nova de Lisboa, Portugal, m2016337@novaims.unl.pt

Pedro Sarmento, Nova Information Management School (NOVA IMS), Universidade Nova de Lisboa, Portugal, psarmento@novaims.unl.pt

Sara Ribeiro, Nova Information Management School (NOVA IMS), Universidade Nova de Lisboa, Portugal, sribeiro@novaims.unl.pt

Teresa Rodrigues, IPRI-NOVA, Instituto Português de Relações Internacionais, Universidade Nova de Lisboa, Portugal, trodrigues@fcsh.unl.pt

Marco Painho, Nova Information Management School (NOVA IMS), Universidade Nova de Lisboa, 1070-312 Lisbon, Portugal, painho@novaims.unl.pt

This is the Author Peer Reviewed version of the following conference paper published by Springer:

Neto, M. D. C., Nascimento, M., Sarmento, P., Ribeiro, S., Rodrigues, T., \& Painho, M. (2019). A Dashboard for Security Forces Data Visualization and Storytelling. In I. Ramos, R. Quaresma, P. R. D. Silva, \& T. Oliveira (Eds.), Information Systems for Industry 4.0: Proceedings of the 18th Conference of the Portuguese Association for Information Systems (pp. 47-62). (Lecture Notes in Information Systems and Organization; Vol. 31). Springer International Publishing. https://doi.org/10.1007/978-3-030-14850-8_4, which has been published in final form at https://doi.org/10.1007/978-3-030-14850-8_4

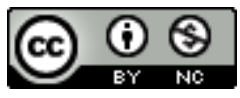

This work is licensed under a Creative Commons Attribution-NonCommercial 4.0 International License. 


\title{
A dashboard for security forces data visualization and storytelling
}

Miguel de Castro Neto, Nova Information Management School (NOVA IMS), Universidade Nova de Lisboa, Portugal, mneto@ novaims.unl.pt

Marcel Nascimento, Nova Information Management School (NOVA IMS), Universidade Nova de Lisboa, Portugal,m2016337@ novaims.unl.pt

Pedro Sarmento, Nova Information Management School (NOVA IMS), Universidade Nova de Lisboa, Portugal, psarmento@ novaims.unl.pt

Sara Ribeiro, Nova Information Management School (NOVA IMS), Universidade Nova de Lisboa, Portugal, sribeiro@novaims.unl.pt

Teresa Rodrigues, IPRI-NOVA, Instituto Português de Relações Internacionais, Universidade Nova de Lisboa, Portugal, trodrigues@ fcsh.unl.pt

Marco Painho, Nova Information Management School (NOVA IMS), Universidade Nova de Lisboa, 1070-312 Lisbon, Portugal, painho@ novaims.unl.pt

\begin{abstract}
Being security assumed as a basic right of citizens in the current model of democratic rule of law, optimal resources allocation altogether with budgetary constraints are a key component. In fact optimal resources allocation and budgetary constraints oblige an increasingly careful strategic management, adapted to demographic reality. The SIM4SECURITY project aims to build a technological solution to support decision making regarding security, based on the development of a GIS model and in the implementation of demographic scenarios. This model will allow policy makers, leaders and forces of command units and services in the planning and rational affectation of resources adjusted to local dynamics in crime prevention and crime fighting. To communicate the SIM4SECURITY results and support decision making, a data visualization and storytelling approach was adopted by creating dashboards containing the various dimensions and perspectives of the information were elaborated and are presented. The obtained outcomes show that dashboards are an important visual tool in the decision-making process by providing meaningful insights regarding security and in the location-allocation of security forces.
\end{abstract}

Keywords: dashboards; crime data; demographic data; SIM4SECURITY

\section{INTRODUCTION}

Security is a fundamental right of citizens and is a complex phenomenon associated to a framework of unpredictable global emerging threats and uncertainties, that are hard to perceive and operationalize in the traditional model of security systems. This complexity forces the State to establish an appropriate institutional framework for internal security action and resources allocation (Teixeira, Lourenço \& Piçarra, 2006), while population's safety becomes a central issue and demographics a strategic vector (Rodrigues, 2014). Demographic projections were prepared (Bravo, 
2016) up to 2040, disaggregated by sex, year and municipality, revealing considerable changes on the Portuguese population in the next years. These new demographic trends can be described as a triple ageing phenomenon: less youngsters, a progressively older working population group, and a high increase of elderly population. If the latter can be seen as an improvement on the health system and the social and economic conditions in Portugal, with the consequent increase of the life expectancy, the demographic decrease of the other two age groups is very concerning, especially because such changes are not uniform throughout the territory. While in the country side there is a general decrease of population in all age groups, which originates the depopulation of the Portuguese rural areas, the urban areas see the decrease of young and working age groups and a serious increase of the elderly age group, in some cases ascending to $100 \%$ in the next 30 years. Besides the burden imposed to the social welfare system, with less taxpayers and more pensioners, implying a reformulation of this system, a review of the security forces distribution is of paramount importance, especially due to this new reality in the location of the senior population. In the rural areas, it is expected to observe more elders living alone or with other elders in isolated places (more vulnerable and facing ageing-associated diseases). In the urban areas, with different (weaker) relationships with neighbors and (higher) criminality patterns, elder will be more exposed to insecurity. The current allocation of security forces was defined in the 1990's. With the recent demographic and social changes in the Portuguese population, a new distribution model is required, to guarantee an adequate, proportional and effective response of the security forces to the population needs. Indeed, security is closely related with demographic and urban dynamics, new criminal realities and the risks of natural disasters.

This multiplicity of interlinked variables requires new approaches to deal with this complexity namely reinforcing technological competences and increasing capabilities regarding security intelligence. The SIM4SECURITY (Forecast and Spatial Analysis Model for Public Security, Ref. PTDC/ATPDEM/1538/2014) project aims to assist decision making process and optimize resources namely: 1) adequacy of police distribution according to citizens characteristics; 2) study of spatial and temporal dynamics of groups at risk and impact assessment in police offer; 3) deploying police forces; and 4) planning of the number and type of effectives needed for each region. Within this framework a dynamic database and model supported by a Geographic Information System (GIS) was developed to integrate georeferenced data and to provide the possibility of correlate data based on its geographic location. The value of GIS in the public security management arises directly from the benefits of integrating a spatial decision-making technology into a field with a solid need to address numerous critical spatial decisions. The necessary data sources, that sometimes are provided in different systems and operated by different agents, turn the task of GIS in a very challenging job. A land use cover change model (LUCC) was also implemented to predict future urban populated land use. This study included the following objectives: to build LUCC maps, up to 2040, focused on 
the evolution of urban areas and in the transitions from the other land use classes to urban land use (Ribeiro et al., 2018); to create dasymetric maps (Semenov-Tian-Shanky, 1911 cited by Petrov, 2012) which allow the association to each type of land use, according to a given population density, the corresponding (projected) population; and, to determine the population living in the areas of responsibility of each police station. Additionally, this third objective allows, in conjunction with other GIS spatial analysis tools such as the calculation of distances by road network from each police station, the determination of the population living at a given distance, thus, identifying which of the police stations must be relocated to minimize that distance and improving the support to population. To prepare the spatial modeling of the LUCC maps, Ribeiro et al. (2018) used the Land Change Modeler (LCM), from TerrSet software. As input, LCM needs land use maps from two different periods in time, with the same characteristics. LCM analyses the changes, models the potential of transition, and makes the prediction of the future change, using a neural network (multi-layer perceptron). The demographic, crime and future scenarios development will be reinforced with visualization techniques to facilitate discussion and improve communication among stakeholders.

One of the visualization techniques that could be used to improve communication are dashboards and its concept has been proposed by analogy with other types of dashboards to promote the development of very practical types of information systems that have a direct impact for instance, in decision making (Adam \& Pomerol, 2008). Dashboards are defined as a visual display of the most important information needed to achieve one or more objectives; consolidated and arranged on a single screen so the information can be monitored at a glance (Few, 2006). Indeed, dashboards are linked to the need to cut through the ever-increasing volumes of data available in the corporate information systems (Paine, 2004). As dashboards combine different variables to reveal relations that would be difficult to identify when analyzing data separately, they are a good way to represent the information in the framework of SIM4SECURITY project. Dashboards leverage on visual information to support decision-making in multiple contexts, and they have been found helpful to increase awareness and support the decision-making process, thus improving the outcomes (Workman, 2008). Regarding public security, they have been proposed to mitigate security related issues (Bhatt et al., 2010; Meynard et al., 2008; Posuniak et al., 2018; Reiter et al., 2016; Rodger and Pendharkar, 2007), showing the importance to gather a succinct picture of the available indicators that authorities need to decide in the most adequate manner. Agencies implementing such tools can easily analyze statistical data to determine where crimes and traffic accidents occur, what types of crime are increasing and decreasing, and where community nuisances like vandalism and noise complaints commonly occur. Agencies can then use that data to shape agency policy and determine where to focus personnel and other crime-fighting resources.

The aim of this paper is to describe the data warehouse implementation that stores the data regarding the SIM4SECURITY project and present the dashboards elaborated with this data. The resulting 
dashboards are an effective way to support decision-makers to create insights about the demographic and crime data in the framework of SIM4SECURITY project, and to create location-allocation scenarios for security forces.

This paper is organized as follows. Section 2 portrays the description of the data collection and its interpretation. Section 3 shows the design and conception of the analytical model. The implementation of the dashboard is presented in Section 4. Some final considerations are included in Section 5 .

\section{DATA COLLECTION AND INTERPRETATION}

To the development of the dashboard, Business Intelligence tools are used for the collection and management of transactional data and its transformation and usage in a multidimensional data model.

Concerning the data sources to be used for the development of the data model, the following information was collected:

- Demographic and social economic data obtained through Statistics Portugal (INE);

- Crime data by municipality obtained through Direcção-Geral da Política de Justiça (DGPJ);

- Police stations, location and allocation of police officers provided by Guarda Nacional Republicana (GNR);

- Demographic projections computed by researchers of NOVA Information Management School (NOVA IMS);

- Map of the Administrative regions of Continental Portugal (CAOP) obtained through the Directorate-General for Territorial Development (DGT); and

- Land Cover Land Use (LCLU) map for Continental Portugal for 2012 and LCLU map projections for 2030 and 2040, computed by researchers of NOVA IMS.

The socioeconomic data included in the data model refers to educational levels of population, labor indicators (employment and unemployment rates), social welfare system (social benefits, pensions, power of purchase, mean income, unemployment subsidies) and municipality budget for different activities (environment, sports, culture). Population data is disaggregated by age group, sex and is provided by municipality and parish (the lower level of the Portuguese administrative divisions).

Crime data from Portugal are publicly available from DGPJ (Directorate-General for Justice Policy). DGJP is the body, within the Ministry of Justice, responsible for the justice statistical data. Empowered by the National Statistics Institute, it is entrusted with the collecting, use, treatment and analysis of the justice statistical data as well as the dissemination within the national statistical 
framework. DGPJ provides official justice statistics, namely the crimes recorded by the different security forces, per year (since 1993), type of crime (levels 1 - class, 2 - subclass and 3 - crime designation) and geographic location (NUTS, district and municipality). The level 1 (class type) distinguishes crimes as: crimes against people, crimes against property, crimes against cultural identity and individual integrity, crimes against life in society, crimes against the State, crimes against pet animals, and crimes typified in specific legislation. Each of these classes are divided in subclasses.

The data regarding police stations and the location and allocation of police officers was only provided by GNR, that is a police force that acts mainly in rural areas. The police stations data refers to theirs action areas (i.e. the parish or parishes that are patrolled by the police officers that belong to certain police station), the hierarchy in which a police station belongs (i.e. Comando, Destacamento e Posto Territorial) the number of police officers allocated to a police station and the coordinates of a police station location.

The demographic projections refer to the data collected from the census 2011, that served as the basis to compute the demographic projections for 2030 and 2040 by parish. To compute the projections, the cohort-component method was used.

The administrative regions data is available from DGT (Directorate-General for Territorial Development). DGT is the national public institution responsible for the public policies of territorial management and urbanism as well by the creation and maintenance of reference geographic databases.

The LCLU map for 2012 is based on the Corine Land Cover 2012 provided by the European Environmental Agency (EEA) and is composed by eight LCLU classes. The LCLU projections for 2030 and 2040 were obtained using the Land Change Model (LCM).

After a filtering process, the indicators and attributes were selected, resulting in seven tables. In this filtering process the rational was to join the indicators regarding police, crime and demography, for its spatial location (i.e. by municipality or parish depending on the data availability).Through these tables with transactional data, the indicators and attributes were extracted, transformed and loaded in analytical tables through an extraction, transformation and load (ETL) process, that allowed the elaboration of a data warehouse. The indicators and the description of their attributes are presented in the following tables.

\begin{tabular}{|l|l|}
\hline Attributes & Description \\
\hline DICOFRE & Parish code \\
\hline Actuação & Security force responsible for the parish \\
\hline Comando & GNR Comando responsible for the parish \\
\hline
\end{tabular}


de Castro Neto et al. / Implementation of a dashboard for security forces data visualization

\begin{tabular}{|l|l|}
\hline Destacamento & GNR Destacamento responsible for the parish \\
\hline Posto & GNR Posto territorial responsible for the parish \\
\hline PostoID & Posto territorial code \\
\hline Efectivo & Number of police officers allocated to a Posto territorial \\
\hline Longitude & Longitude of the Posto territorial location \\
\hline Latitude & Latitude of the Posto territorial location \\
\hline
\end{tabular}

Table 1 - Police officers table (Efectivos) (data privacy: private; source: GNR).

\begin{tabular}{|l|l|}
\hline Attributes & Description \\
\hline Município & Municipality designation \\
\hline DICO & Municipality code \\
\hline Índice & Social economic index code \\
\hline Valor & Social economic value \\
\hline
\end{tabular}

Table 2 - Social economic table (socecon_data2011) (data privacy: public; source: INE).

\begin{tabular}{|l|l|}
\hline Attributes & Description \\
\hline Índice & Social economic index code \\
\hline Description & Social economic index description \\
\hline
\end{tabular}

Table 3 - Social economic metadata table (socecon_meta) (data privacy: public; source: INE).

\begin{tabular}{|l|l|}
\hline Attributes & Description \\
\hline DICOFRE & Parish code \\
\hline Nome & Parish designation \\
\hline Pop_2011 & Population by parish for 2011 \\
\hline Pop_2030 & Estimated population by parish for 2030 \\
\hline Pop_2040 & Estimated population by parish for 2040 \\
\hline
\end{tabular}

Table 4 - Population table (pop_summary) (data privacy: public/private; source: INE/NOVA IMS).

\begin{tabular}{|l|l|}
\hline Attributes & Description \\
\hline DICOFRE & Parish code \\
\hline Classe & Land cover/land use (LCLU) class \\
\hline Area_Km2 & LCLU area in square kilometres \\
\hline Area_ha & LCLU area in square hectares \\
\hline Ano & LCLU reference year \\
\hline
\end{tabular}

Table 5 - LCLU table (uso_solo) (data privacy: private; source: NOVA IMS).

\begin{tabular}{|l|l|}
\hline Attributes & Description \\
\hline Território & Territorial unit nomenclature (NUTS I) \\
\hline Distrito & District designation \\
\hline Município & Municipality designation \\
\hline
\end{tabular}


de Castro Neto et al. / Implementation of a dashboard for security forces data visualization

\begin{tabular}{|l|l|}
\hline Ano & Recorded year for the respective crime \\
\hline Eventos & Number of occurrences regarding the respective crime \\
\hline Índice & Intern nomenclature for the crime description \\
\hline
\end{tabular}

Table 6-Crime table (crime_hist) (data privacy: public; source: DGPJ).

\begin{tabular}{|l|l|}
\hline Attributes & Description \\
\hline Classe & Class regarding crime classification (level 1 crime) \\
\hline SubClasse & Sub class regarding crime classification (level 2 crime) \\
\hline Crime & Crime designation and respective code (level 3 crime) \\
\hline Descrição & Crime designation (level 3 crime) \\
\hline Índice & Intern nomenclature for the crime description \\
\hline
\end{tabular}

Table 7 - Crime metadata table (crime_meta) (data privacy: public; source: DGPJ).

\section{ANALYTICAL MODEL DESIGN AND CONCEPTION}

Before data can be structured as a data warehouse, it must be subject to an ETL process. The ETL process is composed by three steps in which data is manipulated, namely; 1) the extract step in which the data is extracted from the different source systems, making it accessible for further processing; 2) the transform step in which the data is subject to a set of rules to transform the data from the source to the target; and 3) the load step in which the data is loaded for a database.

In the extract step the data was gathered/provided from the different sources (described in the previous section) in the form of excel files (demographic, social economic, crime, police stations and demographic projections data), vector files for CAOP and land cover and land use for Continental Portugal.

For the data transformation the adequate tables structure was created for data storage using Visual Basic scripts. This process was particularly necessary for crime data obtained through DGPJ website, given that the initial data set was provided in a pivot table format. The demographic data was aggregated by age and sex to represent only the population total of the data for 2011 and projections for 2030 and 2040. To have a spatial representation of the allocation of police officers, demographic and crime, this data was joined to CAOP. The LCLU data for each parish was obtained intersecting this data with CAOP. The transactional tables were manipulated and transformed in analytical tables with the use of implemented scripts in SQL Server Integration Services.

These tables were then loaded in a data warehouse and the ETL process was concluded. 
de Castro Neto et al. / Implementation of a dashboard for security forces data visualization

The data warehouse design was developed in a snowflake schema, composed by four facts tables (Demografia - Demography, Crime, Território - Territory e Segurança - Security) and seven dimensions tables (Ano - Year, Socioeconómico - Socioeconomic, Crime, UsoSolo- LandUse, Postos - Stations, Município - Municipality and Freguesia - Parish). In the dimensions tables the attributes and metadata were stored for each component of the data warehouse, while in the facts tables the metrics and indicators were stored, aggregated by type of transaction. The use of a snowflake schema allowed the removal of low cardinality attributes and allow the reduction of tables where is the need of an update if data are modified. As the spatial dimension was normalized into two lookup tables, this aspect allowed the representation of a hierarchy in separate tables (i.e. the hierarchy established in the spatial dimension between Municipio - Municipality and Freguesia - Parish).The dimension Ano-Year is linked with each one the four facts table. This dimension includes the years regarding demographic, territory and security data (i.e data for 2011 and projections for 2030 and 2040) along with the years regarding crime recording (i.e crime data between 1993 and 2016). The Socioeconómico - Socioeconomic dimension is linked to the Demografia-Demography fact table, including in this manner social and economic data provided by the last census relatively to 2011. The Crime dimension stores the classification and description of crime data and is linked to Crime fact table that stores the number of crimes. The fact Territorio - Territory table stores the area of each land use class (Área por solo) by hectar and is linked to to the dimension UsoSolo- LandUse that have the land use nomenclature used to describe land use in the framework of SIM4SECURITY project. The fact Segurança - Security table stores the number of inhabitants by parish along with the population density and the number of police officers by 1000 inhabitants and is linked to the dimension Postos - Stations that have the description of the police stations together with the respective operation parishes of each one. Two spatial dimensions were also defined namely Município-Municipality and Freguesia-Parish. The Município-Municipality dimension is linked to Demografia - Demography and Crime fact table that have their information aggregated to municipality level. The facts Território - Territory and Segurança - Security tables have their information disaggregated to parish level and are linked to the dimension Freguesia-Parish.

Figure 1 presents the snowflake schema of the data warehouse for the SIM4SECURITY project. 


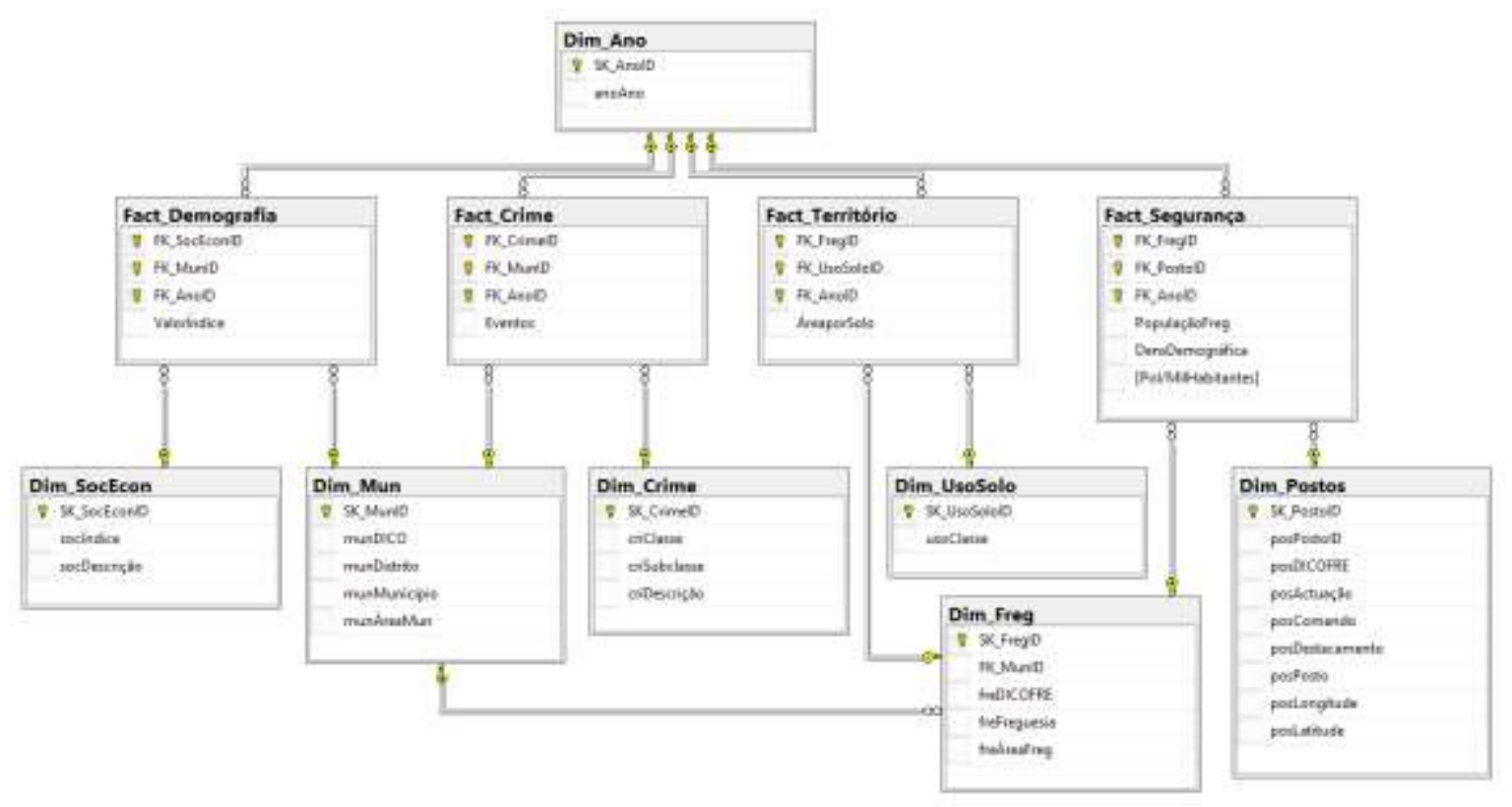

Figure 1 - SIM4SECURITY data model structured as a data warehouse.

\section{DASHBOARD IMPLEMENTATION}

With the elaboration of the dashboard it is possible to create the analytical capabilities necessary to the visualization of metrics and variables combined in a dashboard. Dashboards allow the monitoring, visualization and analysis of critical information in decision support, in a simple and objective manner, allowing the revelation of relations that would be difficult to identify analyzing each dimension individually.

In the framework of SIM4SECURITY project six dashboard reports were elaborated using Power BI Desktop, as described below:

1. An overview report with a high-level perspective of the data under study, gathering the main facts stored in the Data Warehouse (Figure 2).

2. A crime analytical report with in-depth analysis of the relevant metrics and the role of certain socioeconomic indicators as risk factors (Figure 3).

3. A demographic analytical report with in-depth analysis of the relevant metrics and the evolution of demography throughout the country for the next years (Figure 4).

4. A crime details report for a customized, low-level analysis, given the security coverage, location and year (Figure 5).

5. A demographic details report for a customized, low-level analysis, given the land usage, location and year (Figure 6).

6. A socioeconomic details report for a customized, low-level analysis, given the indices correlation to the main facts and location (Figure 6). 
The overview report "Visão Geral" portrayed in Figure 2 shows the four different general themes contained in this dashboard framework: Crimes, population density, police (per 1000 inhabitants) and the concentration of urban areas by municipality. On the left side of the dashboard it is possible to observe an overall summary from each of the themes displayed in the maps. On the bottom it is also possible to check the estimation of one of the above-mentioned themes through time, clicking on a municipality of a specific map theme

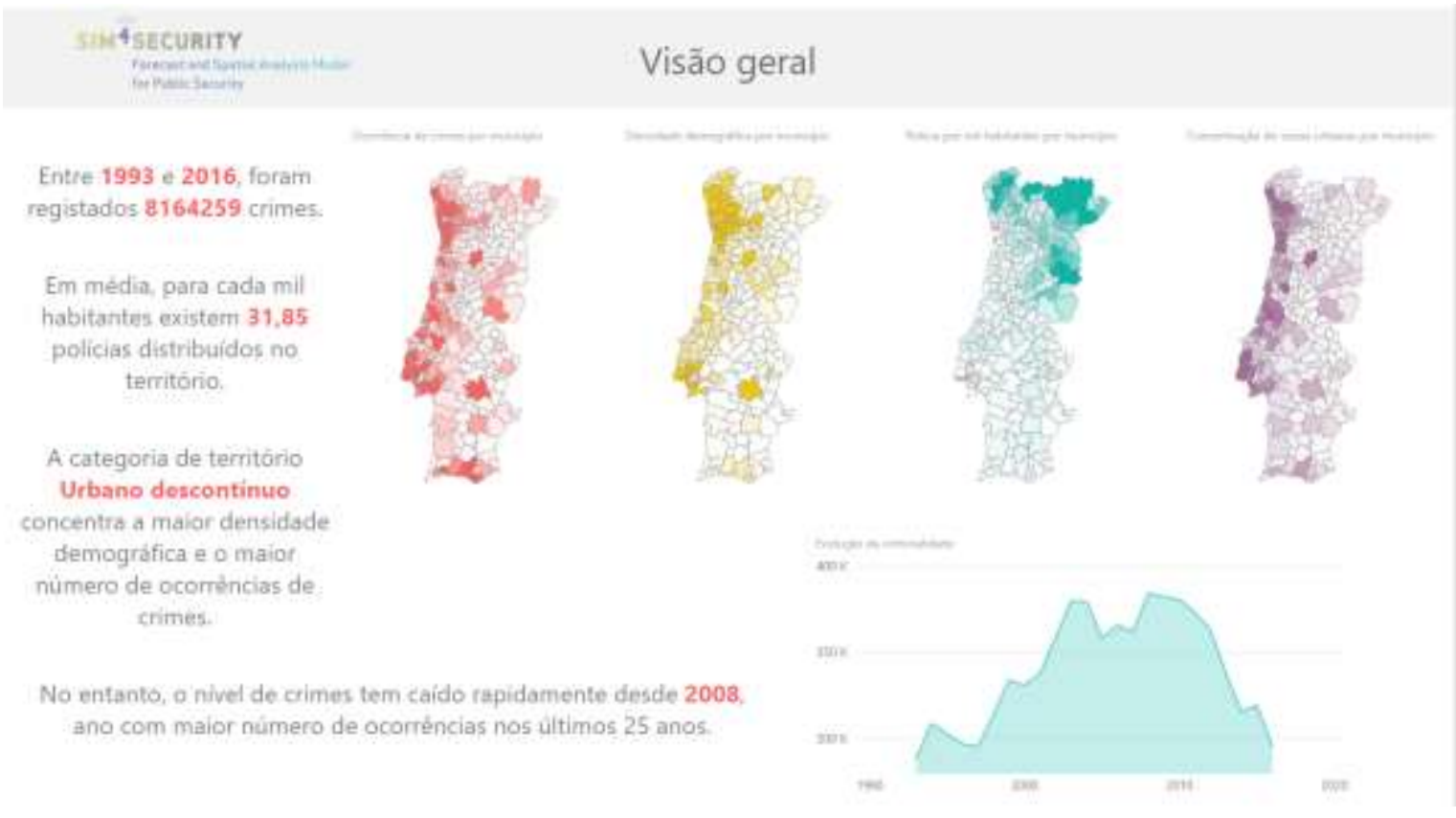

Figure 2 - Overview dashboard view.

Figure 3 shows the crime analytical report provided by the determination of correlations between the different socioeconomic indicators. In the provided Figure, education levels and labor parameters are correlated with the crime occurrence. On the top, maps from the different indicators show the values of each by municipality. A pie chart on the bottom presents the percentage of each class, and correlation matrices between crime and school dropout and crime and unemployment rate are also depicted. Some remarks are provided in the left. The analysis can also be focused on one given municipality, by clicking on the map on the desired one. 


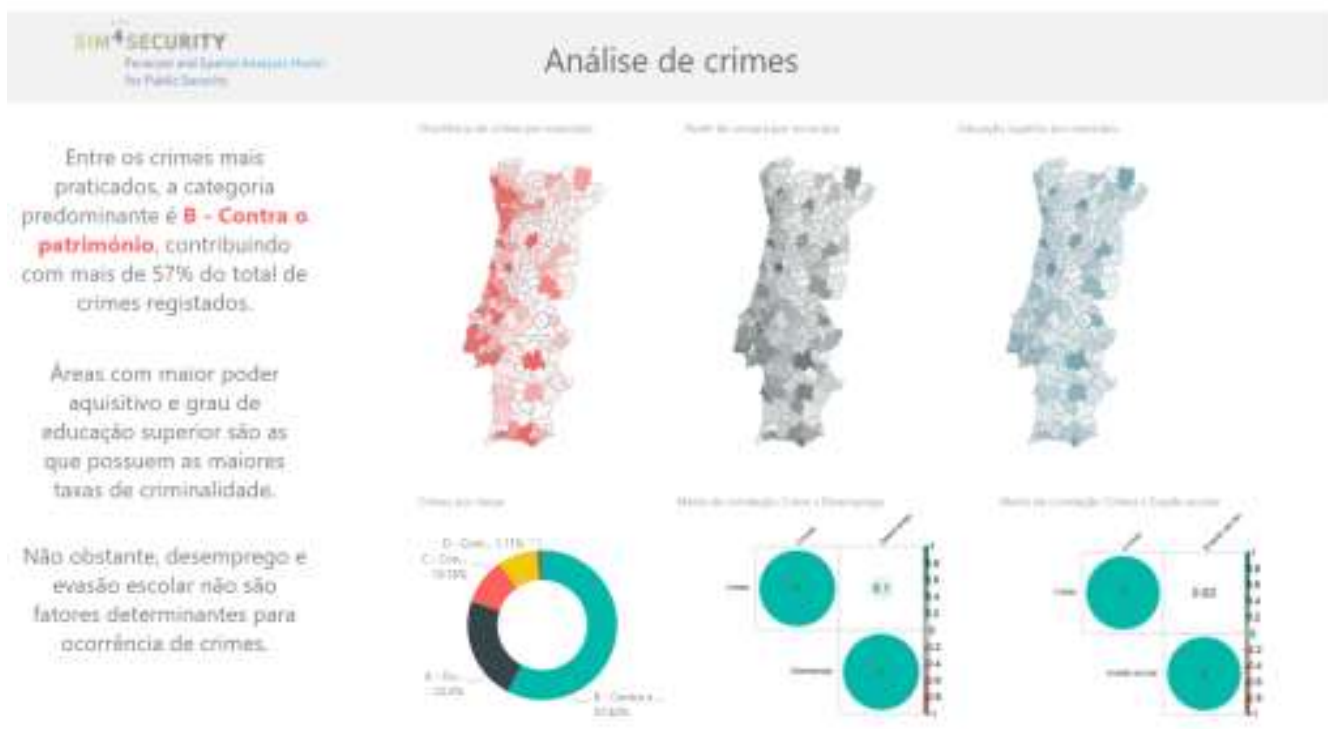

Figure 3 - Crime Analysis dashboard view.

Figure 4 provides the analysis of population throughout the territory. Maps of population density in three different time periods, 2011, 2030 and 2040, are shown in the top of the report. A chart of the population growth is depicted in the bottom, as well as some figures of the different land uses. A summary regarding population characteristics is presented on the left side of the report. By clicking in one of the municipalities in the maps, the interface changes to specifically characterize that indicated municipality.

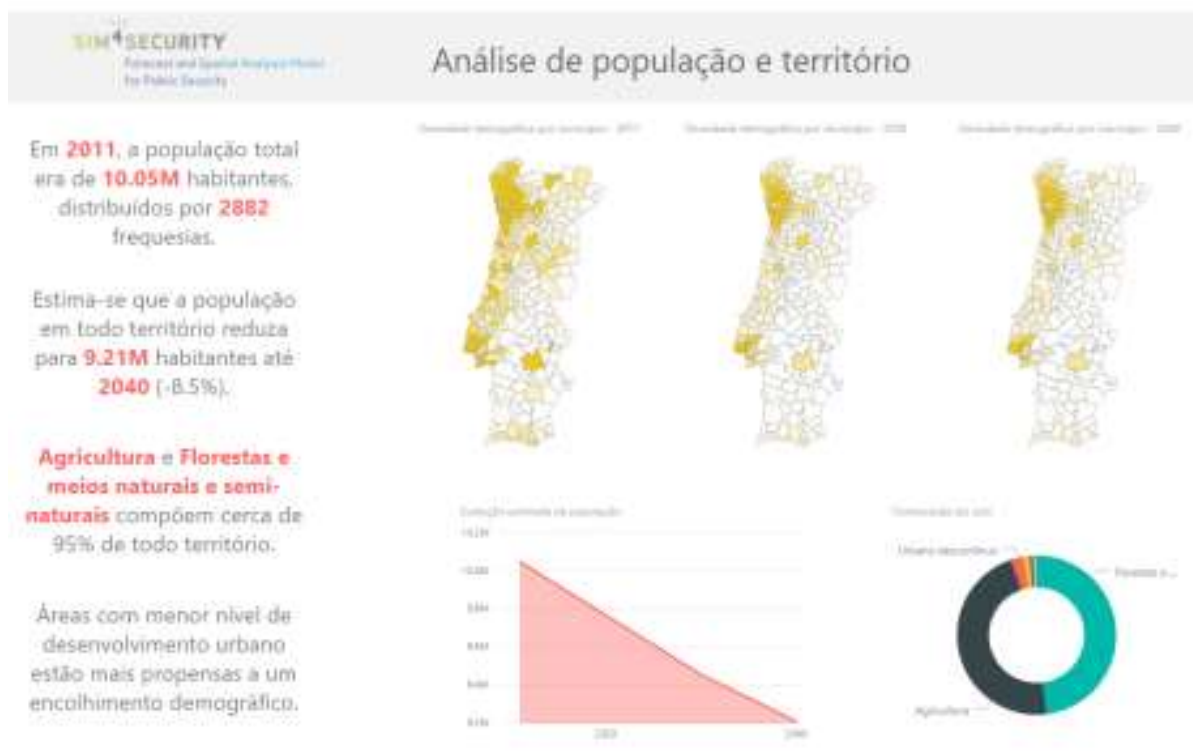

Figure 4 - Population and territory dashboard view. 
Figure 5 gathers the relationships between criminality and security forces. On the left side of the report, an animated distribution of the security forces (provided in a ratio per 1000 inhabitants) is presented in time, where it is possible to observe the concentration of security forces in the north sea coast and in Lisbon areas. In the top of the report, a chart shows the top 10 municipalities with the highest number of recorded crimes (throughout time). A pie chart provided the crimes per class (in percentage). On the bottom, the top 10 crimes (by level 3 - designation) with highest number of recorded crimes and the variation of level 1 class crimes are shown. With the exception of the latter, the other four views can be customized by the year of occurrence. This report can be incremented with additional data, specifically the criminality projections up to 2040 , once they are finalized.

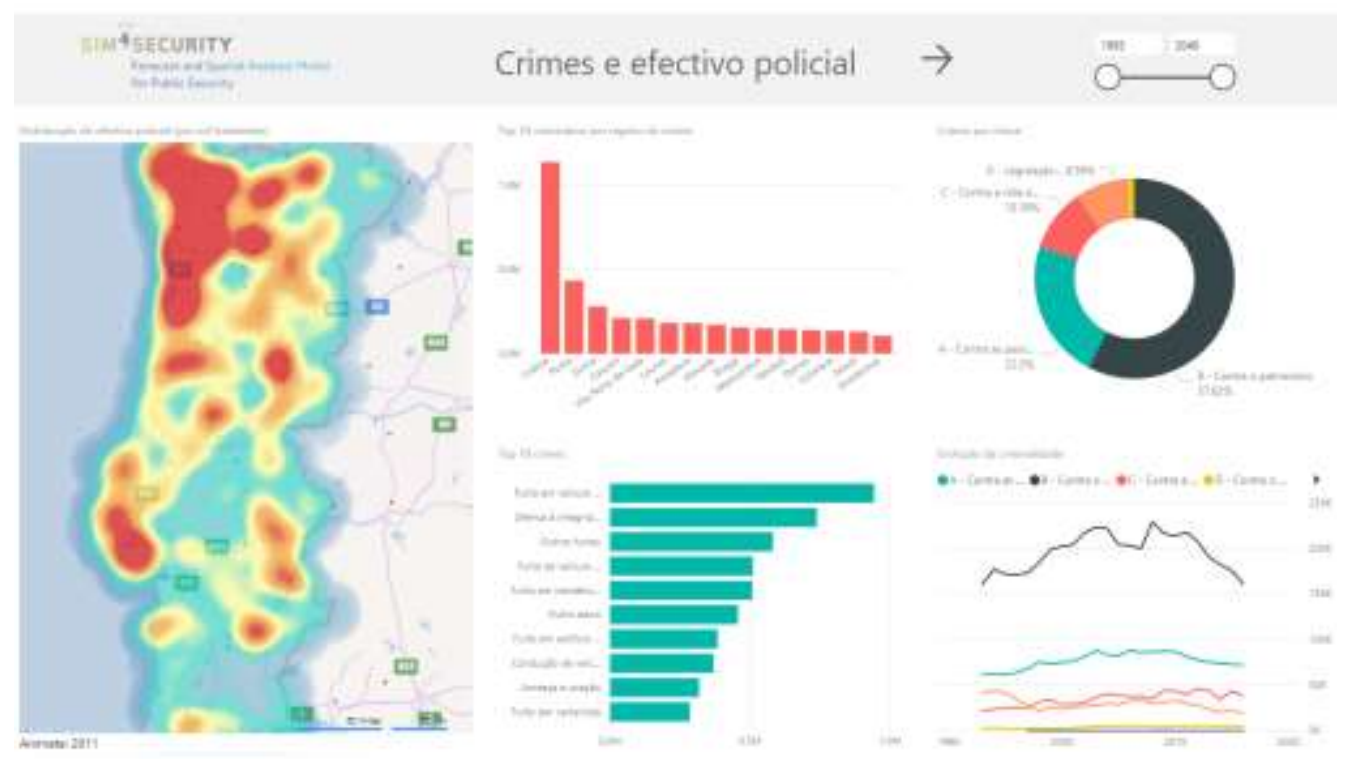

Figure 5 - Crime and security coverage details view.

Figure 6 provides additional details to the population and territory indicators. The population density is shown by municipality in the left side. A bar chart indicates the population by district and a pie chart shows the distribution of the land uses in mainland Portugal (top). The bottom of this view reveals the area of each municipality and the variation of the population, provided by the demographic projections. In this view, it is possible to visualize these indicators in different time periods. 


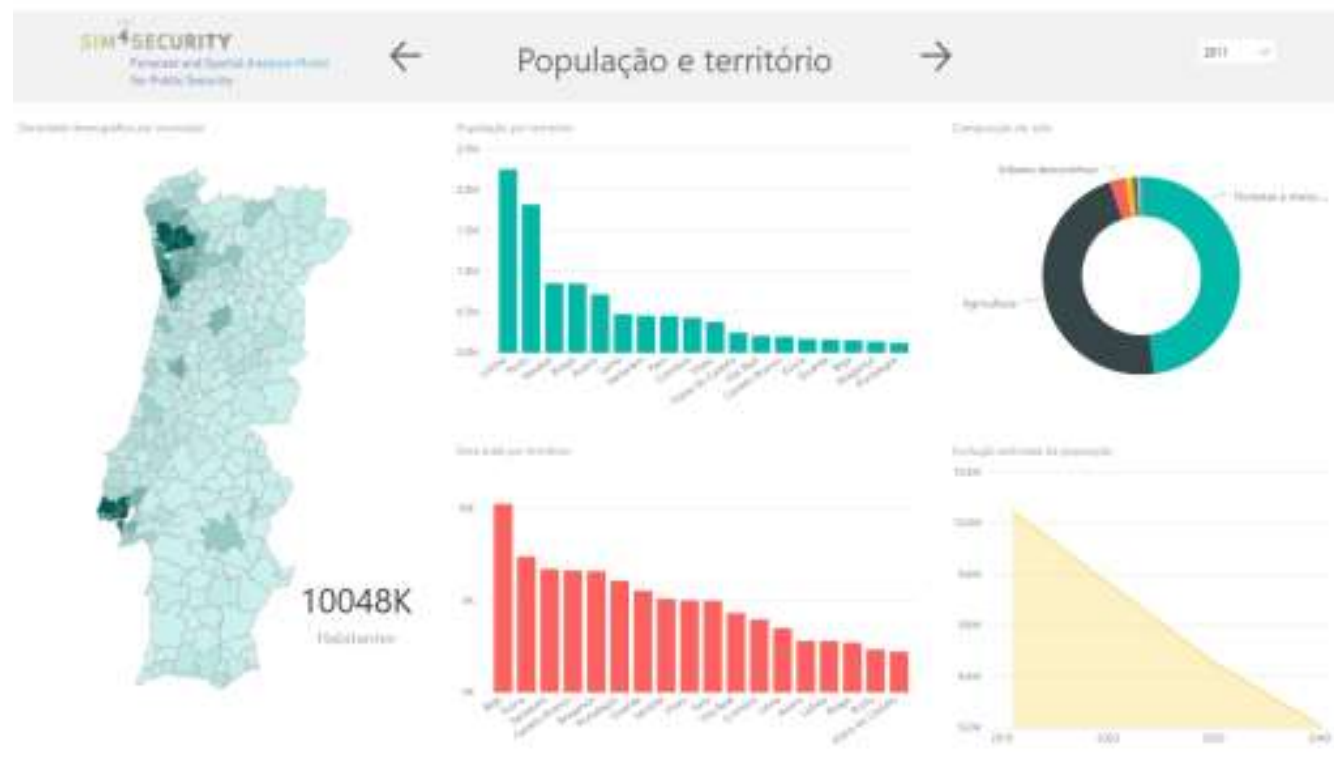

Figure 6 - Population and territory details view.

Finally, the details of the socioeconomic indicators are provided in the view presented by Figure 7. This view is customized by the socioeconomic indicator and by the year. A map, on the left side, presents the distribution of the selected socioeconomic indicator, by municipality, throughout mainland Portugal. A bar chart, by district, shown the same indicator, in the corresponding average value, on the top, and by municipality, on the bottom. A correlation matrix is presented, providing the relation between the different data dimensions for the selected year. This graphical analysis is accompanied by some remarks, containing a summary of what is observed in the view.

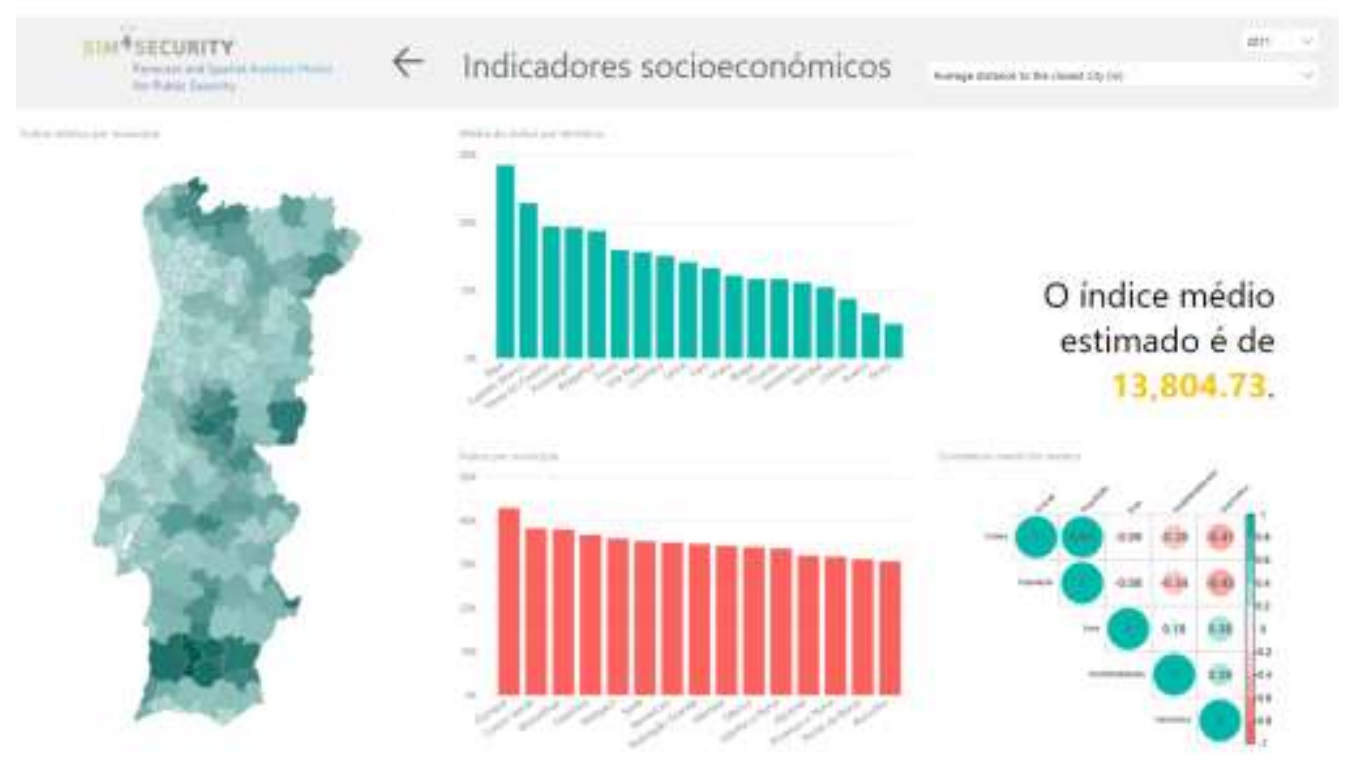

Figure 7 - Social economic indicators view. 
The prepared dashboard enables additional analysis that previously could only be observed in separate, in the format of a paper report. It is now easier to look at different data displays (charts and the geographic distribution of a variable represented in a map) at a time, that can be customized by selecting the year or the specific desired indicator. Additional to this advanced analysis, the dashboard allows the simultaneous visualization of the different data dimensions and correlation among them.

It is relevant also to refer the analytical potential brought by the adoption of a business intelligence approach a dimensional database model since it support data navigation within the hierarchies of the different dimension (when available) as it is presented in Figure 8 where it is possible to observe the drill-down capability within the crime type dimension.

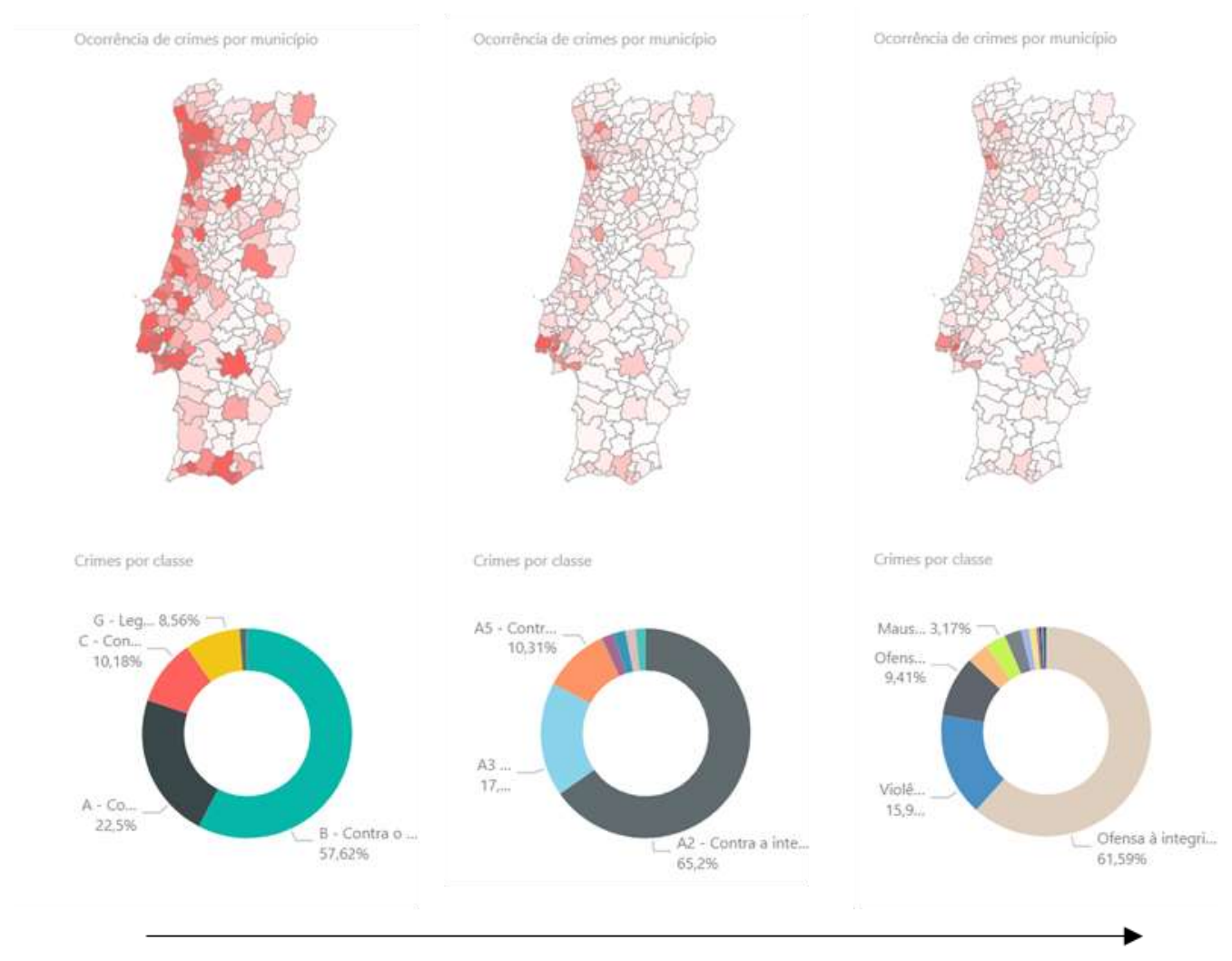

Figure 8 - Navigation within the crime type hierarchy.

\section{CONCLUSION}

The distribution optimization of police forces along mainland Portugal territory is the main goal to be achieved in SIM4SECURITY project. To achieve this goal a GIS model was elaborated along with the development of future demographic and crime scenarios. The amount of data that was collected from different sources, represented a challenge in which for being able to have insights for decision making purposes, this data had to be subject to an ETL process. A data warehouse was then 
elaborated, where the data collected was stored. In order to support analytical capabilities this data warehouse is very important in various aspects namely to provide interconnection between the various dimensions and metrics of the variables in study and to feed the dashboards developed in the framework of the SIM4SECURITY project.

The multidimensional model approach adopted in the SIM4SECURITY project data warehouse was fundamental for data visualization and storytelling to support the dashboard construction and furthermore to allow its dynamic behavior which is critical for visual analysis and insights generation by manipulating and filtering the available facts under the different dimensions.

The resulting dashboards allowed a better understanding of the relations between crime and demographic variables and showed that they are a very useful tool that could aid in the decisionmaking process to optimize the allocation of security forces along the mainland Portugal territory.

The key points observed by these reports are:

- Crimes and population are in constant decline over the past years. Population is expected to shrink $8.5 \%$ by 2040 , while crime is close to reaching an all-time low (considering the historical data collected for the past 25 years). These findings reinforce the high correlation shared between these two variables.

- GNR's security forces are mostly concentrated in the countryside, especially in northern Portugal (measured by one police officer per thousand inhabitants). Given that over $95 \%$ of the country's land usage refers to agriculture and forests, and the urbanization rate is relatively low, this phenomenon could be caused by the higher pace to which non-urban areas are being "depopulated".

- Urban areas are more likely to have higher crime rates. They also present higher purchasing power per capita and education levels. Meanwhile, unemployment and school dropout rates have shown no correlation to the crime phenomena.

- Over 57\% of all crime records in Portugal refer to crimes against property. This category also showed higher variance throughout the years when compared to other crime categories.

Despite the interesting insights provided by the dashboards, the data used to elaborate them, and the data warehouse, several limitations were identified, namely: 1) the crime data is disaggregated only until municipality level, while population data is disaggregated to parish level; 2) the data regarding security forces is only for GNR, that have their main actuation areas in rural zones; 3) the DGPJ database have some year gaps regarding some crimes. Overcoming these limitations would certainly result in better insights retrieved from the dashboards since with the presently available data it is only possible to present information that can be useful in macro decision-making regarding crime (i.e. to adjust national and regional allocation of police forces). 
For future developments it would be interesting to have crime records at parish level from both national Portuguese police forces (i.e. PSP and GNR), the number of police forces and the actuation areas for PSP also at parish level. With this additional data it would be possible to make the analysis at local level, providing a better disaggregated view for an optimized, efficient location-allocation of security forces.

\section{REFERENCES}

Adam, F., Pomerol, J. C. (2008). Developing Practical Decision Support Tools Using Dashboards of Information, in F. Burnstein and C. W. Holsapple (Eds.), Handbook on Decision Support Systems 2, Springer, Berlin, Heidelberg, 151-173.

Bravo, J. (2016). Projecções de População Residente a Nível Concelhio - Metodologia. Universidade Nova de Lisboa, Information Management School, Novembro 2016.

Few, S. (2006). Information Dashboard Design: The Effective Visual Communication of Data, O'Reilly.

Meynard, J. B., Chaudet, H., Texier, G., Queyriaux, B., Deparis, X., Boutin, J.P., 2008. Real time epidemiological surveillance within the armed forces; concepts, realities and prospects in France, Revue $D$ Epidemiologie et de Sante Publique, 56(1), 11-20, doi: 10.1016/j.respe.2007.11.003.

Paine, K. D. (2004). Using Dashboard Techniques to Track Communication, Strategic Communication Management, 8, 5, 30-33.

Petrov, A. (2012). One Hundred Years of Dasymetric Mapping: Back to the Origin, The Cartographic Journal, 49 (3), p. 256-264, doi: 10.1179/1743277412Y.0000000001.

Posuniak, P., Kowalski, K., Wrobel, T., Kresa, P. (2018). The equipment of a modern police patrol car and the safety of the crew, in 11th International Scientific and Technical Conference on Automotive Safety Proceedings, April 18-20, 2018, Casta Papiernicka, Slovakia.

Reiter, R.M., Ganchenko, K., Charalambidou, A. (2016). Requests and counters in Russian traffic police officer-citizen encounters Face and identity implications, Pragmatics and Society, 7 (4), 512-539, doi: 10.1075/ps.7.4.01mar.

Ribeiro, S., Cabral, P., Henriques, R., Bravo, J., Rodrigues, T., Painho, M. (2018). "Modelação do crescimento urbano para a distribuição eficaz das forças de Segurança. O caso português". Proelium, Vol. VII(14), 39-62.

Rodger, J., Pendharker, P. (2007). Lessons learned from testing, analyzing and problem solving an online Military Watchboard Medical Decision Support System (MWMDSS) application: Potential implications for civilian and e-Government organizations, in Remenyi, D. (ed.), ICEG 2007: Proceedings of the 3rd International Conference on E-Government, 215 pp., 3rd International Conference on e-Government, September 27-28, 2007,Montreal, Canada.

Rodrigues, T. (2014). Population dynamics. Demography matters, in Globalization and International Security. An overview, NOVA Publishers, New York, 57-74.

Teixeira, N. S., Lourenço, N., \& Piçarra, N. (2006). Estudo Para a Reforma do Modelo de Organização do Sistema de Segurança Interna. Relatório preliminar, IPRI.

Workman, M. (2008). An experimental assessment of semantic apprehension of graphical linguistics. Computer Human Behavior, 24(6), 2578-2596. 